ORIGINAL ARTICLE

\title{
Clinical Comparison of Three Tooth-colored Full-coronal Restorations in Primary Maxillary Incisors
}

\author{
Muskaan Nischal ${ }^{1}$, Teena Gupta ${ }^{2}$, Manjul Mehra ${ }^{3}$, Gunmeen Sadana ${ }^{4}$
}

\begin{abstract}
Aim: The aim of this in vivo study was to evaluate the surface texture, anatomical form, marginal integrity, marginal discoloration, and secondary caries of three different types of crowns in primary anterior teeth at different time intervals of 3,6, and 9 months.

Materials and methods: Total 45 primary maxillary incisors were randomly selected and divided into three groups of 15 each: group I—strip crowns (Pedoform strip crowns, 3M, United States), group II-zirconia crown (kids-e-crown, India), and group III-luxa crown (DMG, Germany). All the full-coronal restorations were evaluated at 3,6, and 9 months. The modified USPHS criteria were used to evaluate different parameters. Data were collected and the nonparametric test (Chi-square) was used to analyze the intergroup data.

Results: Statistically nonsignificant difference was observed for most of the parameters except marginal integrity and secondary caries. Resin strip crowns showed maximum cases with distorted marginal integrity and secondary caries.

Conclusion: Zirconia crown performed best among the three full-coronal restorations. Luxa crown performed similar to zirconia crown. It can be used as an alternative economical esthetic full-coronal restoration for primary maxillary anterior incisors.

Clinical significance: This study illustrates the advantage of the temporization material as a full-coronal restoration option in primary maxillary anterior teeth.

Keywords: Luxa crown, Resin strip crown, USPHS criteria, Zirconia crowns.

International Journal of Clinical Pediatric Dentistry (2020): 10.5005/jp-journals-10005-1842
\end{abstract}

\section{INTRODUCTION}

Orodental trauma and early childhood caries often result in loss of the clinical crown structure in primary maxillary anteriors. ${ }^{1}$ Early loss of these teeth has deleterious effects, viz. space loss, speech problems, tongue thrusting habit, and psychological effects. To restore such severely damaged teeth with pulpal involvement is always a challenging task for the dentist. With the advancement of dental materials and techniques in conservative dentistry, a multitude of esthetic treatment modalities has been introduced for the management of dental caries and trauma in the primary dentition. ${ }^{2}$

Full-coronal esthetic restorations are advocated for restoration of primary anterior teeth, such as resin composite strip crowns, ${ }^{3}$ ready-made crowns like preveneered stainless steel crowns (PVSSC), ${ }^{4}$ and the recently introduced prefabricated primary zirconia crowns. ${ }^{5}$

Resin strip crowns are widely used in primary anterior teeth. Strip crowns have following advantages: good esthetics, simple to use, repairability, and provides great parent and patient satisfaction. Its disadvantages are technique sensitivity, needs adequate tooth structure for retention, patient cooperation, and fractures easily under trauma. ${ }^{6}$

In 2008, zirconia crowns were introduced to pediatric dentistry as an alternative restorative option. Zirconia is a crystalline dioxide of zirconium that has mechanical properties similar to those of metals and its color is similar to that of teeth. ${ }^{7}$ Advantages of the pediatric zirconia crowns include excellent esthetics, resistance to fracture, biocompatibility, reduced plaque accumulation, color stability, and potentially less technique sensitivity. Zirconia crowns require extensive tooth reduction due to their inflexibility and thickness as compared to resin strip crowns, in order to provide passive fit of crown to the tooth. ${ }^{8}$
${ }^{1}$ Department of Pediatric and Preventive Dentistry, Sri Guru Ram Das Institute of Dental Sciences and Research, Amritsar, Punjab, India

2,3 Department of Pedodontics, Sri Guru Ram Das Dental College and Hospital, Amritsar, Punjab, India

${ }^{4}$ Department of Pedodontics and Preventive Dentistry, Sri Guru Ram Das Institute of Dental Sciences and Research, Amritsar, Punjab, India

Corresponding Author: Muskaan Nischal, Department of Pediatric and Preventive Dentistry, Sri Guru Ram Das Institute of Dental Sciences and Research, Amritsar, Punjab, India, Phone: +91 7986107178, e-mail: muskaannischal@gmail.com

How to cite this article: Nischal M, Gupta T, Mehra M, et al. Clinical Comparison of Three Tooth-colored Full-coronal Restorations in Primary Maxillary Incisors. Int J Clin Pediatr Dent 2020;13(6):622-629.

Source of support: Nil

Conflict of interest: None

In recent times, bis-acryl composite-based temporization material has become the material of choice for temporization purposes owing to its improved mechanical properties. Luxa crown is a temporization material that has been widely used to fabricate temporary crowns in permanent dentition but its use has been sought in primary dentition also. As primary teeth are going to last for few years only, this material can provide a durable, long-lasing, and economical restoration. Each method of restoration has its own distinct advantages and disadvantages. ${ }^{5}$

The present study was done to compare three different full-coronal esthetic restorations on severely mutilated primary anterior teeth, i.e., resin strip crowns, zirconia crowns, and luxa crown. The modified USPHS criteria were used to compare various parameters.

(0) Jaypee Brothers Medical Publishers. 2020 Open Access This article is distributed under the terms of the Creative Commons Attribution 4.0 International License (https://creativecommons.org/licenses/by-nc/4.0/), which permits unrestricted use, distribution, and non-commercial reproduction in any medium, provided you give appropriate credit to the original author(s) and the source, provide a link to the Creative Commons license, and indicate if changes were made. The Creative Commons Public Domain Dedication waiver (http://creativecommons.org/publicdomain/zero/1.0/) applies to the data made available in this article, unless otherwise stated. 


\section{Materials and Methods}

The present in vivo study was conducted to compare three tooth colored full-coronal restorations-resin composite strip crown, zirconia crown, and luxa crown. The research protocol was followed and carried out after approval of the ethical committee of Sri Guru Ram Das Institute of Dental Sciences and Research, Amritsar.

For this study, 45 patients were randomly selected who compiled with the following inclusion criteria.

\section{Inclusion Criteria}

- Carious deciduous maxillary incisors indicated for pulpectomy

- Proximal decay (affecting two or more dental surfaces)

- No root caries

- Presence of at least two-third root structure radiographically

- Presence of at least one-third crown structure

- No mobility of tooth

- No gingival recession present

- No hypoplastic tooth

- No deleterious oral habits

- Fractured teeth

- Children with behavior scale of 1 and 2 (Frankl's rating scale).

\section{Sample Size and Procedure}

\section{Preoperative Assessment}

Medical and dental history of all the patients was noted along with clinical signs and symptoms and preoperative intraoral periapical radiographs were taken.

\section{Sample Distribution}

A random sample of 45 deciduous carious/grossly decayed maxillary incisors requiring pulpectomy was selected and they were equally distributed in three groups of 15 each as follows:

- Group I: Resin composite strip crowns (Pedoform strip crowns, 3M, United States)

- Group II: Prefabricated primary zirconia crowns (kids-e-crown, kids-e-Dental, India)

- Group III: Luxa crown (DMG, Hamburg, Germany)

\section{Group I}

The material of choice for coronal buildup for this group was strip crown. An appropriate-sized strip crown was selected to fabricate the crown. Crown cutting was done by reducing the tooth interproximally by $0.5-1.0 \mathrm{~mm}$. The incisal edge was reduced by 1.5 $\mathrm{mm}$ using a fine-tapered bur. The labial and lingual surfaces were reduced by 1 and $0.5 \mathrm{~mm}$, respectively. Feather edge was created at the gingival margin. The strip crown was adapted to the cingulum of the anterior tooth by cutting the gingival margin using scissors. A hole was made on the palatal surface of the crown for the removal of excess material. The tooth surfaces were etched for 15 seconds with a $37 \%$ phosphoric acid solution and then rinsed thoroughly with water. Tooth surfaces were dried with air pressure and a layer of bonding agent was applied. Then it was polymerized for 20 seconds. The composite-filled celluloid crown was then inserted and excess resin was removed. The material was light-cured and strip crown was peeled off. Occlusion was checked and adjusted accordingly. Finishing was done with shofu discs (super snap Mini-kit) and burs (shofu composite finishing kit, Tokyo, Japan) (Fig. 1).
Group II

The material of choice for coronal buildup for this group was zirconia crown (kids-e-crown). The selection of the appropriate crown size was performed prior to the tooth preparation. Incisal edge was reduced to provide clearance of about $2 \mathrm{~mm}$ and 1-2 $\mathrm{mm}$ interproximal contacts were broken followed by labial and lingual reduction of $0.5-1 \mathrm{~mm}$ on both sides of the crown (according to manufacturer's instructions). A feather edge of 1-2 $\mathrm{mm}$ subgingivally was created to facilitate a passive fit. Air dry the crown and completely fill it with resin-modified glass ionomer luting cement (RelyX Luting 2 Cement, 3M ESPE). Remove excess cement using explorer and floss (Fig. 2).

\section{Group III}

The material of choice for coronal buildup for this group was luxa crown (DMG, Germany). Following steps were followed for this novel approach of restoring the tooth with custom-fabricated crowns with temporization material. Crown cutting was done, reducing the tooth by $\sim 1.5 \mathrm{~mm}$ from all sides. An appropriate-sized strip crown was selected to fabricate the crown. Shade matching was done in accordance with the adjacent teeth, and strip crown was loaded with the temporization material using automix syringe. Loaded strip crowns were then placed on the prepared tooth within 40 seconds and removed while the material is still in the elastic stage (1.45-2.20 minutes after start of mixing). The material was then allowed to set extraorally, and strip crown was peeled (DMG, Germany). The preparation was thoroughly cleaned with water spray, dried, and separating media was removed. The finished crown was cemented over the prepared crown using the resin-modified glass ionomer RelyX Luting 2 Cement from 3M ESPE. Occlusion was checked and adjusted accordingly (Fig. 3).

\section{Treatment Evaluation}

Patients were recalled after 3,6 , and 9 months to evaluate the surface texture, anatomical form, marginal integrity, marginal discoloration, and secondary caries using the Modified United States Public Health Service (USPHS) criteria.

\section{Statistical Analysis}

Descriptive and analytic statistics of surface texture, anatomical form, marginal integrity, marginal discoloration, and secondary caries were done between resin strip crown, zirconia crown, and luxa crown. As the data of all the parameters did not follow normal distribution, the nonparametric test (Chi-square) was used to analyze the intergroup data.

\section{Results}

The statistical analysis revealed no changes in surface texture at 3- and 6-month interval when zirconia crown, luxa crown, and resin strip crown were compared. At the end of 9 months, clinically luxa crown and resin strip crown showed 13.3 and $20 \%$ rough surface texture, respectively, as compared to zirconia crown but statistically results were not significant ( $p$ value $=0.207$ ) with a Chi-square value of 3.150 (Table 1).

When the anatomical forms of zirconia crowns, luxa crowns, and resin strip crowns were compared, at the end of 3 months no change in the anatomical form was shown by any group. At the end of 6 months, $13.3 \%$ of resin strip crown showed slightly loss of material as compared to others. But at 9-month interval, $13.3 \%$ of total or partial loss of the bulk was observed in both luxa and resin 

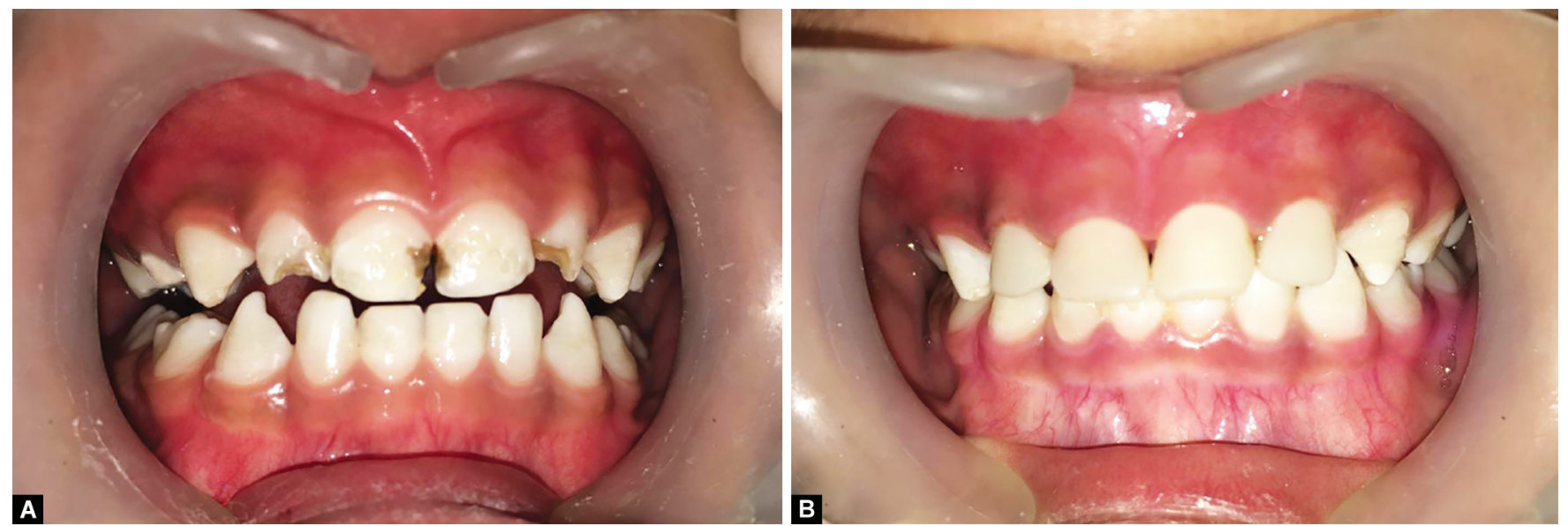

Figs 1A and B: (A) Preoperative photograph showing carious 51, 52, 61, 62; (B) Postoperative photograph showing resin strip crowns 51, 52, 61 , 62
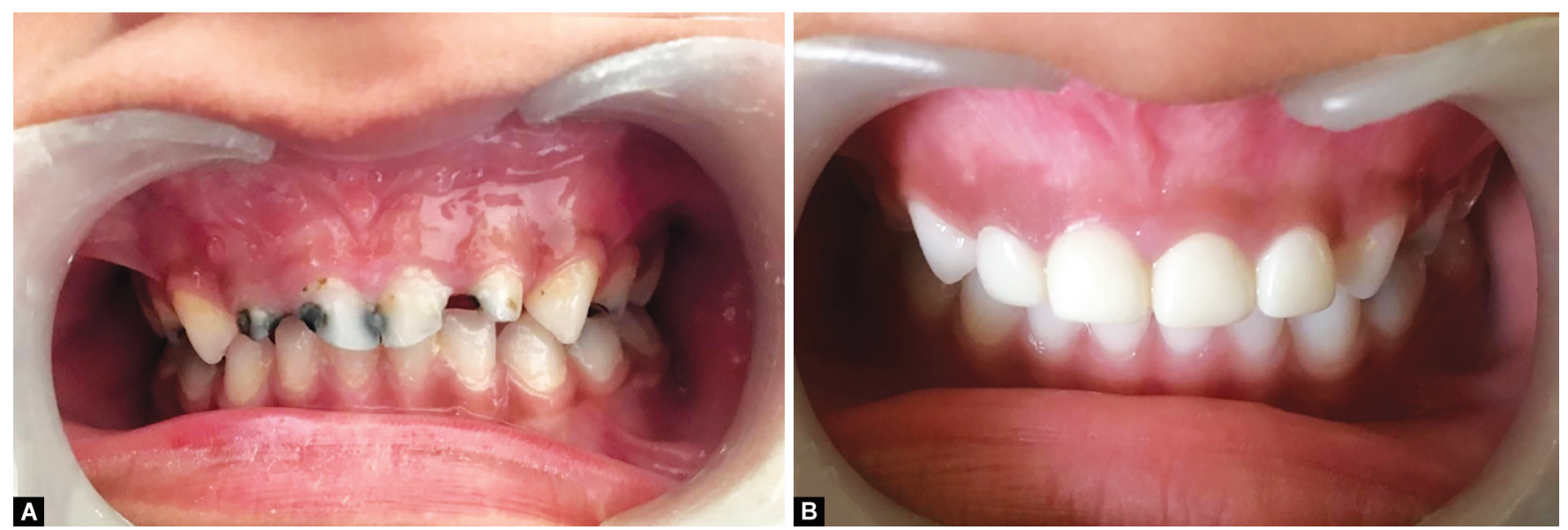

Figs $2 A$ and B: (A) Preoperative photograph showing carious 51, 52, 61, 62; (B) Postoperative photograph showing zirconia crowns 51, 52, 61,62
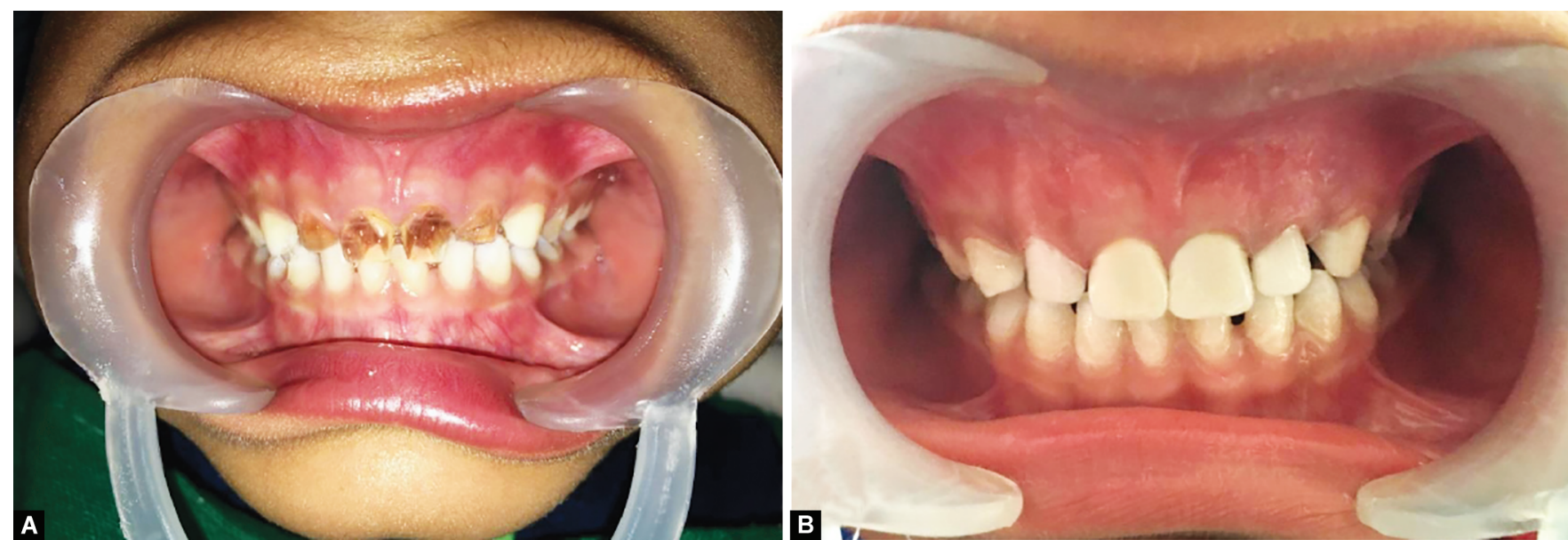

Figs 3 A and B: (A) Preoperative photograph showing carious 51, 52, 61, 62; (B) Postoperative photograph showing luxa crowns 51, 52, 61, 62

strip crowns. However, difference were not significant ( $p$ value $>$ 0.05 ) at 6- and 9-month intervals (Table 2).

Intergroup comparison of zirconia crown, luxa crown, and resin strip crown showed sound marginal integrity at the end of 3 months. At 6-month interval, discontinuity in marginal integrity was shown by $20 \%$ of cases in the resin strip crown group. Significant differences were found when all three groups were compared at the end of 6 months ( $p$ value $=0.040$ ) with a Chi-square value of
6.429. But at the end of 9 months, discontinuity was exhibited by both luxa crown and resin strip crown. However, results were not significant after 9 months' follow-up ( $p$ value $=0.2310$ ) (Table 3 ).

When the marginal discoloration of zirconia crowns, luxa crowns, and resin strip crowns was compared, no discoloration was observed at 3 months' follow-up. At the end of 6 months, slight discoloration was seen in $6.6 \%$ of luxa crown and $20 \%$ of resin strip crowns whereas strong discoloration was seen by both luxa 

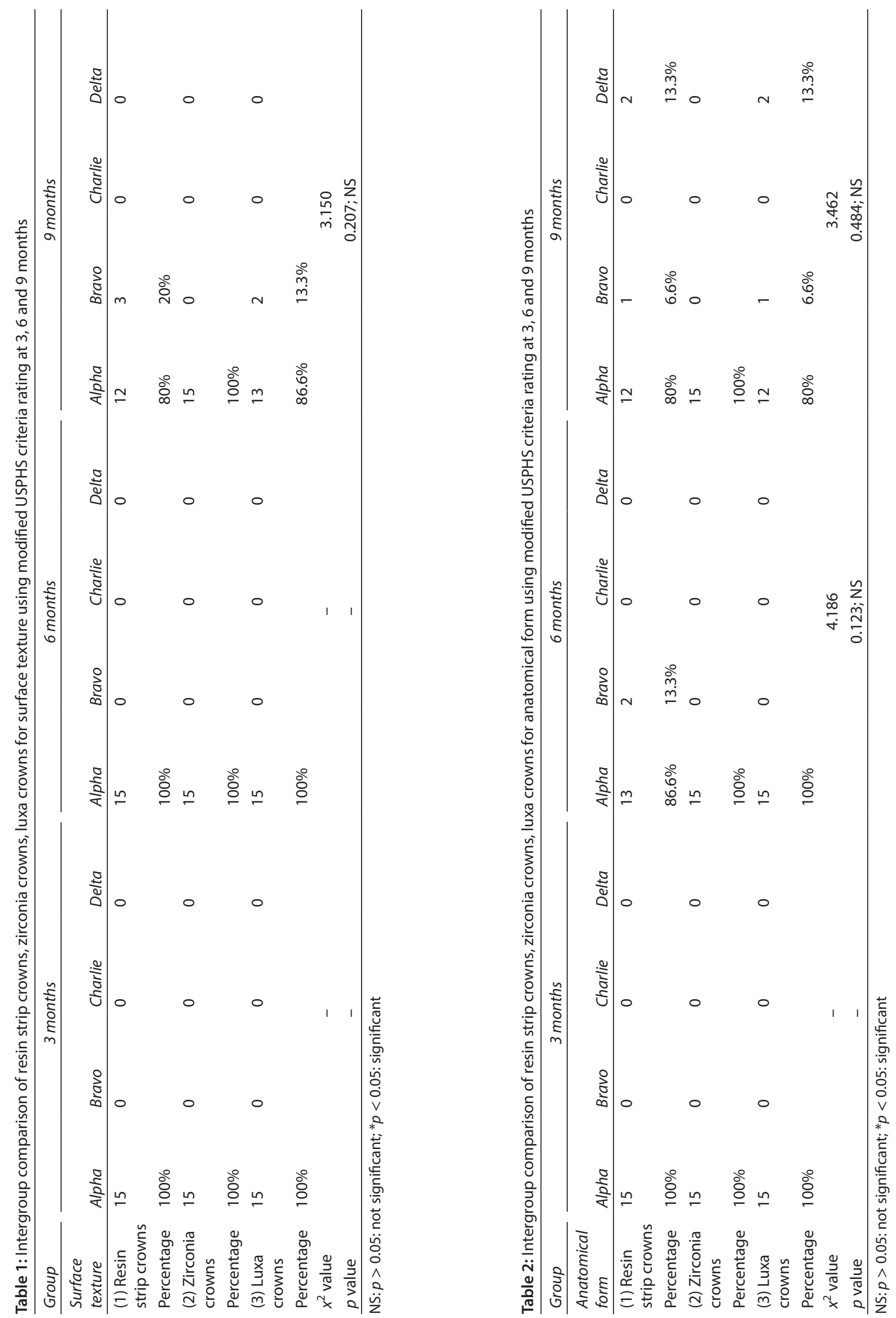


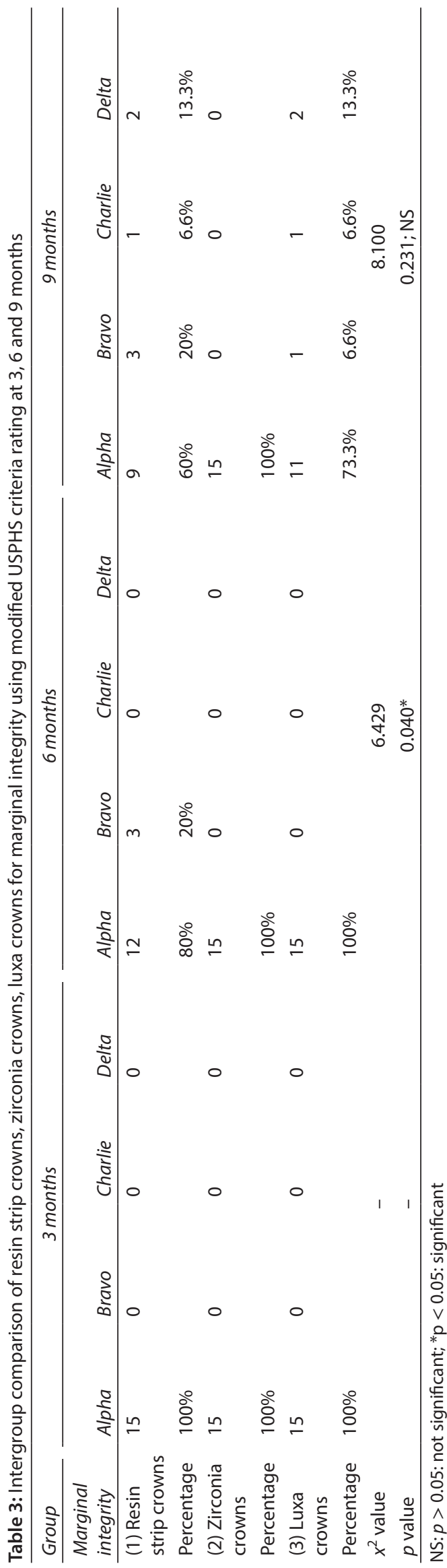

crown and resin strip crown at 9 months' follow-up. Nonsignificant results were obtained at 6- and 9-month intervals ( $p$ value $=0.146$ and 0.217) (Table 4).

Secondary caries of zirconia crowns, luxa crowns, and resin strip crowns were compared; statistically significant difference was found between them at 9 months ( $p$ value $=0.012$ ) with a chi-square value of 8.780. No secondary caries was seen in zirconia crown and luxa crown at 3-, 6-, and 9-month intervals. But resin strip crowns showed $26.6 \%$ of cases with secondary caries (Table 5 ).

\section{Discussion}

Child's oral health represents an important aspect of the overall health. Dental problems can cause alterations in child's general health status, growth, and quality of life. The most common oral health problem is dental caries. Dental caries can occur in any age group but when it affects very young children, it is referred as early childhood caries (ECC). Different stages of ECC have different treatment plans. The treatment option for initial white spots lesions (enamel demineralization) consists of topical fluoride applications, oral hygiene maintenance, and improving eating habits. When dental lesions invade into dentin, tooth restorations are needed. Endodontic treatment followed by full-coronal restoration is generally the treatment of choice when pulp is involved in damaged teeth. $^{9}$

In this present study, following parameters of modified USPHS criteria were used to evaluate various crowns, i.e., surface texture, anatomical form, marginal integrity, marginal discoloration, and secondary caries.

\section{Surface Texture}

In the present study, when intergroup comparison of surface texture was observed at the end of 3 and 6 months, no distortion of surface texture was observed in zirconia crowns, luxa crowns, and resin strip crowns (Table 1).

At the follow-up after 9-month interval, zirconia crowns showed no change in surface texture and luxa crown showed $13.3 \%$ cases of rough surface texture. However, maximum distortion of surface texture was reported in $20 \%$ cases of resin strip crowns, although the difference was statistically insignificant.

Neamat et al. ${ }^{10}$ have shown that fillers tend to fall out from resin materials and the matrix component decomposes when exposed to low pH environments. Good surface texture of zirconia crowns could be due to a highly polished surface, which results in less plaque accumulation. ${ }^{5}$ Luxa crowns showed no significant changes in surface texture after follow-up of 3, 6, and 9 months; it could be because luxa crown as temporization material produces a smooth, glossy surface from the beginning, which eliminates the need for polishing or glaze.

\section{Anatomical Form}

When intergroup comparison of the anatomical form was observed, no differences were found after 3 months' interval. Among all the crowns, zirconia crowns exhibited $100 \%$ success rate after 9 months of postoperative evaluation. For luxa crowns and resin strip crowns, the success rate was $80 \%$ at the 9 months' follow-up. The result of the present study are in accordance with the results of the study carried out by Kupietzky et al., ${ }^{7}$ where he observed clinical and radiographic success of 112 composite resin strip crowns in 40 children. It was determined that the $88 \%$ of crowns were present without any loss of material with a mean follow-up time of 

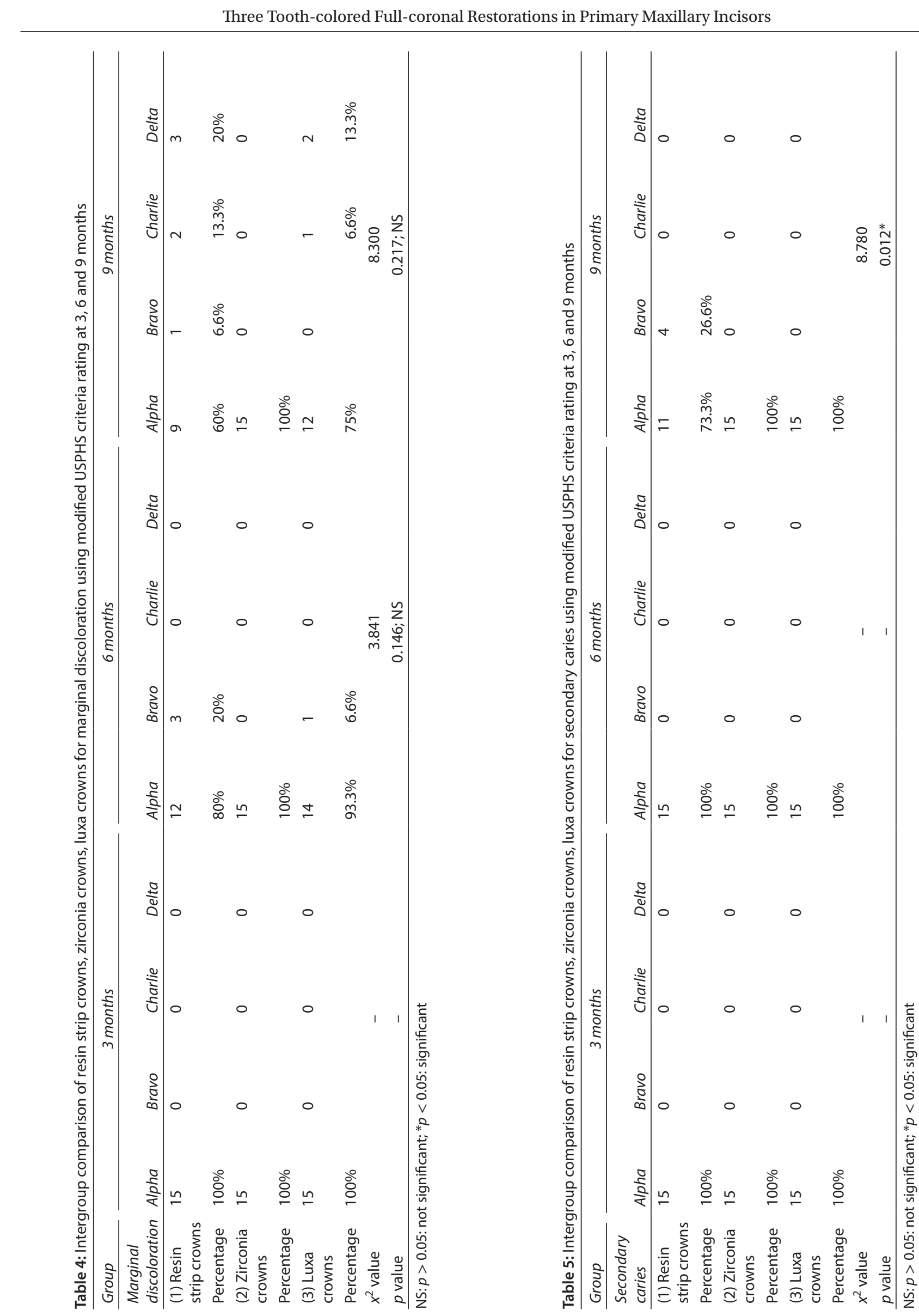

\begin{tabular}{|l|l|} 
International Journal of Clinical Pediatric Dentistry, Volume 13 Issue 6 (November-December 2020) & $\mathbf{6 2 7}$
\end{tabular} 
18 months. Ram and Fuks ${ }^{11}$ found similar results in a retrospective study. They reported $80 \%$ of the resin-bonded composite strip crowns were successful at the final examination after a 2-year follow-up. Walia et al. ${ }^{5}$ showed a success rate of $100 \%$ for zirconia crowns, 95\% for stainless steel crowns (SSCs), and 78\% for strip crowns after 6 months, which is in accordance to our present study when he compared the clinical outcomes of composite strip crowns, PVSSCs, and prefabricated primary zirconia crowns. In a study by Tate et al., ${ }^{12}$ a high failure rate of $50 \%$ was reported for strip crowns over a period of 2 years.

A higher success rate was observed with zirconia crowns followed by luxa crowns and resin strip crowns. This can be explained by the fact that zirconia has a unique ability to resist crack propagation by being able to transform from one crystalline phase to another, and the resultant volume increase stops the crack and prevents it from propagating. ${ }^{13}$

Luxa crown is reliably hard and resistant, with an exceptional fracture toughness of $>2 \mathrm{MPa}$ ensuring stable restorations. A crown fabricated with temporization material is not dependent on the direct bonding of the composite to the tooth material and thus may have better retention properties even in cases where remaining tooth structure is less. This might be the reason for fewer cases of anatomical distortion in the luxa crowns group. Al-Eheideb and Herman ${ }^{14}$ reported a $70 \%$ success rate for 23 teeth with composite resin strip crowns followed between 6 and 27 months. Overall, from the abovementioned retrospective chart studies, the success rate for composite resin strip crowns ranges from 49 to $100 \%$ with follow-up periods from 6 to 27 months. In our study, resin strip crowns showed $80-100 \%$ of success rate from 3 to 9 months. Few cases reported with distorted anatomical form in the resin strip crown group can be attributed to the fact that it is very technique sensitive and affected by moisture.

\section{Marginal Integrity}

All the three crowns had good marginal integrity after 3-month interval of postoperative evaluation (Table 3). At the end of 6 months, zirconia crowns and luxa crowns still exhibited no loss of integrity whereas resin strip crowns showed statistically significant results of $20 \%$ loss of marginal integrity. At 9 months' follow-up, zirconia crowns showed no change in marginal integrity whereas 26.7 and $40 \%$ of loss was seen in luxa and resin strip crowns, respectively, although the difference was statistically insignificant. Taran et al. ${ }^{15}$ compared SSC and zirconia crown preparation techniques and found that the gingival health of zirconia crowns was better than that of SSCs because zirconia crowns provide uniform smooth margins comparable to those of the SSCs. Due to formation of feather edge margins and subgingivally preparation in prefabricated zirconia crowns, they exhibit good marginal adaption to the tooth. ${ }^{16}$ In case of luxa crowns, custom fabrication further ensured good adaption at the margins, and the final restorations exhibited good immediate esthetics. ${ }^{17}$

Distortion in marginal integrity of resin strip crowns can be attributed to the fact that its placement is quite technique sensitive and requires cooperation of the child. Children who are lacking cooperative ability, it is difficult for placement of strip crowns and might affect the longevity of the restorations. ${ }^{18}$ Many other factors may contribute to unsatisfactory marginal adaptation and these includes preoperative tooth conditions, patient factors (habits, occlusion, spacing, or crowding of maxillary anterior teeth), complications during treatment (gingival bleeding, moisture control difficulty), amount of enamel available for bonding, adhesive systems, and composite resin used. ${ }^{19}$

\section{Marginal Discoloration}

All the three crowns had no marginal discoloration after 3-month interval of postoperative evaluation (Table 4). Zirconia crowns showed no discoloration on margins even after 6 and 9 months interval. After 6 months, $20 \%$ of cases of resin strip crowns and $6.6 \%$ cases of luxa crowns showed marginal discoloration. This may be attributed to translucent nature of luxa and resin strip crowns, allowing the discolored tooth color to show through the restoration. ${ }^{7}$ Maximum discoloration was observed in the resin strip crowns at the end of 9 months' interval. The change in marginal discoloration in case of strip crowns is due to its techniquesensitive option, moisture contamination with blood or saliva, which interferes with the bond; sometimes hemorrhage can also alter the shade or color of the material. Zirconia as a tooth material is highly biocompatible and possesses a polished and smooth surface leading to less plaque accumulation and hence less gingival irritation. The esthetic integration of pediatric zirconia crowns is also very good. These crowns look natural and exhibit excellent color stability as comparison to others. ${ }^{20}$ Another study that supported our present study is given by Aiem et al. ${ }^{21}$ and they reviewed preformed pediatric crowns and concluded that the success rate of zirconia crowns was better as compared to resin strip crowns due to less plaque and less gingival irritation.

Salami et al. ${ }^{22}$ compared preveneered SSC, strip and zirconia crowns for parental satisfaction and found parental overall satisfaction was highest for zirconia primary crowns followed by resin strip crowns and PVSSC. Peumans et al. ${ }^{23}$ reported that after 5 years, resin strip crowns showed marginal discoloration in $44 \%$ of cases, which is comparable to our study where $40 \%$ of cases showed discoloration at 9 months' interval.

\section{Secondary Caries}

No signs of secondary caries were found in zirconia crowns and luxa crowns at each interval (Table 5). When intergroup comparison was done, significant results were found at 9-month interval and in our study, $26.6 \%$ of cases of secondary caries were seen in resin strip crowns, which can be due to microleakage caused by polymerization shrinkage. Zirconia crowns are less technique sensitive and more moisture tolerant, though it is cement dependent and therefore chances of secondary caries are reduced. ${ }^{24}$ Due to presence of bis-acryl composite resin in the luxa crown material, chances of polymerization shrinkage is also less because luxa crown does not contain methacrylates, which causes shrinkage after curing. ${ }^{25}$

The absence of a proper preventive strategy could result in caries recurrence. As oral hygiene and diet are critical factors in developing caries, one of the limitations was that there was no control over the oral hygiene and diet of the children; thus, these factors could have influenced caries recurrence rates in children. ${ }^{26}$

The higher success rate for zirconia crowns in our study could be due to its excellent durability, high flexure strength, biocompatibility, smooth and glossy surface, superior corrosion resistance, unique ability to resist crack propagation, and better mechanical properties. Results of the present study showed that luxa crowns performed better than strip crowns due to high fracture toughness and nondependency upon remaining tooth structure for retention and less polymerization shrinkage, although the results were nonsignificant. According to the present study, zirconia crowns 
performed best among all three groups but their high cost still remains a pressing factor among the middle-class population, so luxa crowns can be used as an alternative option to restore primary anterior teeth in these cases.

\section{Conclusion and Clinical Significance}

Esthetic treatment of severely decayed primary teeth is one of the greatest challenges for pediatric dentists. The use of esthetic restoration has become an important aspect of pediatric dentistry. Over the years, numerous techniques for restoring primary teeth have been attempted. The effective and efficient usage of these techniques is complicated due to technical, functional, or esthetic hurdles.

In view of the above, it can be concluded that resin strip crowns have lower success rate and high occurrence of secondary caries. Luxa crowns performed better than strip crowns, which can be due to its high fracture toughness, smooth glossy surface, less technique sensitivity, and nondependency upon remaining tooth structure for retention as it is luted to the tooth. Zirconia crowns performed best among all three groups due to its excellent durability, high flexure strength, biocompatibility, smooth and glossy surface, superior corrosion resistance, unique ability to resist crack propagation, and better mechanical properties but these crowns required greater amount of tooth reduction, limited shade selection, limited potential to alter the shape of the crown, and the cost per crown represented additional potential disadvantages. So, luxa crowns can be used as an alternative option to restore primary anterior teeth in these conditions.

\section{Manufacturers' Names}

- Light cure unit: manufactured by Ivoclar, vivadent, Schaan, Liechtenstein.

- Zirconia crowns: manufactured by Kids-E-crown, kids-E-Dental, India.

- Luxa crowns, Automix Dispenser, Automix Cartridge, Mixing Tips: manufactured by DMG, Hamburg, Germany.

- Strip crown: manufactured by 3M, ESPE, United States.

- Composite syringe: manufactured by Filtek, Z-250 XT, 3M, ESPE, United States.

- Etchant-Gel etchant: manufactured by 3M, ESPE, United States.

- Bonding agent: manufactured by single bond 2,3M, ESPE, United States.

- Dual-core luting cement: manufactured by RELY X luting 2, 3M, ESPE, United States.

- Composite finishing kit: manufactured by Shofu, Shofu Dental Corporation, Kyoto, Japan.

\section{References}

1. Lee JK. Restoration of primary anterior teeth: a review of literature. Pediatr Dent 2002;24:506-511.

2. Muhamad AH, Azzaldeen A, Mai A. Strip crowns technique for restoration of primary anterior teeth: case report. J Dent Med Sci 2015;14(12):48-53.

3. Mendes FM, De Benedetto MS, Zardetto CG, et al. Resin composite restoration in primary anterior teeth using short-post technique and strip crowns: a case report. Quintessence Int 2004;35(9):689-692.

4. Usha M, Deepak V, Venkat S, et al. Treatment of severely mutilated incisors: a challenge to the pedodontist. J Indian Soc Pedod Prev Dent 2007;25(Suppl):S34-S36.

5. Walia T, Salami AA, Bashiri R, et al. A randomised controlled trial of three aesthetic full-coronal restorations in primary maxillary teeth.
Eur J Paediatr Dent 2014;15(2):113-118. DOI: 10.1007/s40368-0130072-1.

6. Sahana S, Vasa AA, Sekhar R. Esthetic crowns for primary teeth: a review. Ann Essen Dentis 2010;2(2):87-93. DOI: 10.5368/ aedj.2010.2.2.87-93.pdf.

7. Kupietzky A, Waggoner WF, Galea J. The clinical and radiographic success of bonded resin composite strip crowns for primary incisors. Pediatr Dent 2003;25(6):577-581.

8. Ashima G, Sarabjot KB, Gauba K, et al. Zirconia crowns for rehabilitation of decayed primary incisors: an esthetic alternative. $J$ Clin Pediatr Dent 2014;39(1):18-22. DOI: 10.17796/jcpd.39.1.t6725r5 $566 \mathrm{u} 4330 \mathrm{~g}$.

9. Kumar R, Sinha A. Restoration of primary anterior teeth affected by early childhood caries using modified omega loops- a case report. Annals of Dental 2014;2(4):24-26.

10. Neamat AB, Han L, Okamoto A, et al. Effect of alcoholic and low $\mathrm{pH}$ soft drinks on fluoride release from compomer. J Esthet Dent 2000;12(2):97-104. DOI: 10.1111/j.1708-8240.2000.tb00206.x.

11. Ram D, Fuks AB. Clinical performance of resin-bonded composite strip crowns in primary incisors: a retrospective study. Int J Paediatr Dent 2006;16(1):49-54. DOI: 10.1111/j.1365-263X.2006.00680.x.

12. Tate $\mathrm{AR}, \mathrm{Ng} \mathrm{MW}$, Needleman $\mathrm{HL}$, et al. Failure rates of restorative procedures following dental rehabilitation under general anesthesia. Pediatr Dent 2002;24(1):69-71.

13. Khatri A. Esthetic zirconia crown in pedodontics. Int J Pedod Rehabi 2017;2(1):31. DOI: 10.4103/ijpr.ijpr_24_16.

14. Al-Eheideb A, Herman N. Outcomes of dental procedures performed on children under general anesthesia. J Clin Pediatr Dent 2004;27(2):181-183. DOI: 10.17796/jcpd.27.2.k3307186n7086r11.

15. Taran PK, Kaya MS. A comparison of periodontal health in primary molars restored with prefabricated stainless steel and zirconia crowns. Pediatr Dent 2018;40(5):334-339.

16. Planells del Pozo P, Fuks AB. Zirconia crowns- an esthetic and resistant restorative alternative for ECC affected primary teeth. J Clin Pediatr Dent 2014;38(3):193-195. DOI: 10.17796/jcpd.38.3.0255q84jt2851311.

17. Gugnani N, Pandit IK, Gupta M, et al. Esthetic rehabilitation of primary anterior teeth using temporization material: a novel approach. Int J Clin Pediatr Dent 2017;10(1):111-114. DOI: 10.5005/ jp-journals-10005-1418.

18. Lopez-Loverich AM, Minerva Garcia MM, Donly KJ. Retrospective study of retention of stainless steel crowns and pre-veneered crowns on primary anterior teeth. Pediatr Dent 2015;37(7):530-534.

19. Manmontri C, Sirinirund B, Langkapint W, et al. Retrospective evaluation of the clinical outcomes and patient and parental satisfaction with resin strip crowns in primary incisors. Pediatr Dent 2018;40(7):425-432.

20. Lopez Cazaux S, Hyon I, Prud'homme T, et al. Twenty-nine-month follow-up of a paediatric zirconia dental crown. BMJ Case Rep 2017;2017:14. DOI: 10.1136/bcr-2017-219891.

21. Aiem E, Smaïl-Faugeron V, Muller-Bolla M. Aesthetic preformed paediatric crowns: systematic review. Int J Paediatr Dent 2017;27(4):273-282. DOI: 10.1111/ipd.12260.

22. Salami A, Walia T, Bashiri R. Comparison of parental satisfaction with three tooth-colored full-coronal restorations in primary maxillary incisors. J Clin Pediatr Dent 2015;39(5):423-428. DOI: 10.17796/10534628-39.5.423.

23. Peumans $M$, Van Meerbeek B, Lambrechts $P$, et al. The 5-year clinical performance of direct composite additions to correct tooth form and position. II. Marginal qualities. Clin Oral Investig 1997;1(1):19-26. DOI: 10.1007/s007840050004.

24. Holsinger DM, Wells MH, Scarbecz M, et al. Clinical evaluation and parental satisfaction with pediatric zirconia anterior crowns. Pediatr Dent 2016;38(3):192-197.

25. Singh A, Garg S. Comparative evaluation of flexural strength of provisional crown and bridge materials-an in vitro study. J Clin Diagnos Res 2016;10(8):ZC72.

26. Talebi M, Parisay I, Khorakian F, et al. A simplified method for the restoration of severely decayed primary incisors. J dent (Tehran) 2015;12(3):177. 